\title{
The search for the Holy Grail and the upper airway resistance syndrome. New data are welcome
}

\author{
A.L. Mena Gutiérrez*,\#, D.O. Rodenstein*
}

The last half of the last year of the 20th century has witnessed the renaissance of medieval tournaments in the field of sleep-related respiratory medicine $[1,2]$. The two champions are valiant and fierce. One is a French American, the other a Scot. They fight over words. But words are not, as it could seem at first sight, trivial matters. They are the substance of ideas and concepts, and much blood has been spilled for ideas and concepts in human history. The fight we are referring to is not one of bloodshed. It is a scientific fight, and thus a polite one. What are the words these two champions fight for? Let us try to summarize the arguments of both parties.

One claims that many human beings suffer from a newly described disease state (the upper airway resistance syndrome) that is different to other disease states, and not a variant, form or degree of a previously recognized disease state. He goes on to state that by not recognizing this newly described disease state, not only are these patients denied a well adapted clinical management, but we are all denied the opportunity to gain new knowledge profitable to these, and other, patients [1].

The other contends that these patients suffer from a mild form or degree of a well-known and characterized disease state (the sleep apnoea/hypopnoea syndrome (SAHS)); that nothing special differentiates these patients from the others suffering the same disease state, except precisely the level of severity of the disease, and that the use of new words to describe what is already known will only introduce confusion in the spirit of both patients and nonspecialized physicians and experts [2].

What are they talking about? They both refer to events that are hidden by the shadows of night. Many people, able to breathe normally while they are awake, experience difficulty from the moment they fall asleep, and become unable to sustain normal ventilation. In humans, to stop breathing beyond a very limited time is not suitable for good health. These people do make efforts to breathe, but these efforts are rendered inefficient, totally or partially, because the air tubing

*Respiratory Division, Cliniques Universitaires Saint-Luc, Université Catholique de Louvain, Brussels, Belgium and ${ }^{\#}$ Laboratorio de Sueño, Instituto Nacional de Enfermedades Respiratorias, México DF, México.

Correspondence: D.O. Rodenstein, Cliniques Saint-Luc, av. Hippocrate 10, 1200 Brussels, Belgium. Fax: 3227642831. is totally or partially collapsed. To stop the progressing asphyxia, sleep is briefly interrupted, the air tubing pops open, effective breathing ensues, and sleep resumes. When the episode is due to a complete collapse of the airway, it is called an apnoea. When collapse is incomplete, tidal volume is so reduced that asphyctic changes take place as the episode proceeds. This is called hypopnoea. The identification of apnoeas and hypopnoeas is partly a matter of measurement techniques, since the minimal quantity of airflow or volume that different instruments can measure varies, and this may determine whether a given episode is called an apnoea or an hypopnoea. Many, though not all patients experiencing the presence of numerous apnoeas/hypopnoeas during sleep, accompanied by as numerous brief interruptions of sleep (sleep fragmentation), develop symptoms and health consequences that legitimate the use of the descriptive term "syndrome" to allude to the whole disease state related to repetitive airway collapse during sleep [3]. One of the main symptoms is excessive daytime sleepiness and its consequences [4]. Among the most studied complications are hypertension [5], coronary heart disease [6] and traffic accidents [7].

It has been suggested that one of the main stimuli that leads to sleep interruption (and thus to apnoea/ hypopnoea termination) is the level of respiratory effort developed by the patient trying to breathe against the collapsed airway [8]. In the early 1990s, Guilleminault et al. [9] reported on a small group of patients with excessive daytime sleepiness and sleep fragmentation but lacking the usual physiopathological characteristics of SAHS: there were no apnoeas or hypopnoeas, and oxygen saturation remained normal throughout sleep. However, the authors found that many episodes of brief arousals were immediately preceded by signs of increased respiratory effort, detected through the use of an oesophageal balloon, and that the brief arousals were followed by a decrease in respiratory effort. A 4-week period of treatment with nasal continuous positive airway pressure (a treatment used in SAHS that splints the airway thus avoiding airway collapse and its consequences) led to normalization of sleep and respiratory efforts, and to a decrease in sleepiness. This was identified as upper airway resistance syndrome (UARS), a new cause of excessive daytime sleepiness.

Is this really a condition different from SAHS? In this issue of the European Respiratory Journal, Guilleminault et al. [10] present data on spectral 
analysis of sleep and sleep architecture in matched groups of normal subjects and patients with UARS, sleep apnoea syndrome (SAS) and sleep hypopnoea syndrome (SHS). They contend that according to the data, SAHS and UARS patients have different brain activity during sleep and cannot therefore be considered as similar.

The paper by Guilleminault et al. [10] requires some comments. They recruited 12 patients with UARS who are described as representative of the general UARS patient. However, only male patients were recruited (perhaps because patients had to be matched to patients with SAS, mainly male). The sex ratio of UARS in the general population being 1:1 [11], future studies will have to determine whether the findings presented apply also to females with UARS. Each UARS patient was matched for age, sex and body mass index (BMI) to a normal subject and a patient with SAS (perfect matching) and to a patient with SHS (matching was less successful for this group). There were no obese subjects in this study. The reasons for excluding obesity are clearly delineated in the Discussion. Nevertheless, it remains true that many (though far from all) patients seen in sleep clinics around the world have a BMI in the 30s, whereas the average BMI in the study published here is $25 \mathrm{~kg} \cdot \mathrm{m}^{-2}$. Again, one does not know whether the results presented here also apply to less lean (or more obese) patients. Even if it may be true that the 12 UARS patients are representative of the average UARS patient, one may doubt that the 12 SAS patients represent the average SAS (or SHS) patient. All patients were similarly more sleepy than the normal subjects according to the Epworth Sleepiness Scale and the Multiple Sleep Latency Test. All patients had mild facial dysmorphia, and did not differ between each other. Patients with SAS and SHS had apnoeas and hypopnoeas accompanied by falls in arterial oxygen saturation $\left(\mathrm{Sa}_{\mathrm{a}} \mathrm{O}_{2}\right)$, whereas patients with UARS did not. The latter, however, had numerous nonapnoeic, nonhypopnoeic events, so that the total respiratory disturbance index was similar in the three groups. Even the level of respiratory effort, measured as oesophageal pressure swings, was not different between the three groups of patients.

Sleep data are intriguing. It appears that these three groups of sleepy patients slept less than the control group of normal nonsleepy subjects. Patients with the UARS spent $1 \mathrm{~h}$ "awake" during the recording nighttime, whereas the figure is more than $2 \mathrm{~h}$ in the SAS and SHS groups. This is attributed in the latter two groups, to numerous arousals lasting more than $30 \mathrm{~s}$, which is certainly an unusual finding in the literature. As previously described, all patient groups had increased amounts of stage 1 non-rapid eye movement (REM) sleep, and decreased amounts of stages 3 and 4 non-REM sleep (less reduced in UARS than in SAS patients) and REM sleep. Power spectrum analysis, performed from central leads, required the elimination of all arousals, brief or long, as well as of all artefacts. Thus, we are presented with data from artificially constructed "stable" sleep, in disease states characterized precisely by the instability of sleep. From a spectral analysis point of view, sleep in UARS is similar to the sleep of normal subjects submitted to experimental sleep fragmentation with auditory stimuli: persistency of high delta power throughout the night, and increased alpha power. In patients with SAS, both the alpha and delta band power was lower than in UARS. Finally, normal subjects had more delta power and less alpha power than both groups of patients.

These are the data. Their true significance is difficult to perceive. The authors suggest that patients with UARS are very sensitive to stimuli coming from the airways or chest wall, that they are very reactive to these stimuli, thus avoiding airway closure (at the price of increased efforts and thus of increased sleep fragmentation), and that they maintain a high degree of "arousability" throughout the night, explaining their daytime sleepiness. Patients with SAS would have either a blunted sensibility to peripheral stimuli, a blunted reactivity to these stimuli, or both, thus allowing airway closure to occur, also leading to sleep fragmentation and daytime sleepiness.

There is clearly not enough knowledge yet to accept or refute the interpretation given by GuILLEMINAULT and coworkers $[1,3,9,10]$. Are these differences between upper airway resistance syndrome and sleep apnoea syndrome patients just trivial, random variability? Do they represent a new insight that will eventually unveil important physiopathological information? One cannot forget that all these patients had a similar degree of subjective and objective sleepiness in spite of what appear as clear differences in sleep macro- and microstructure. Although well matched groups were studied (according to the fashionable concepts of evidenced based medicine), more patients with upper airway resistance syndrome will need to be studied to confirm these findings. Respiratory physicians are familiar with the notions of "fighter" and "nonfighter", that tried to explain why some patients with chronic obstructive pulmonary disease "allowed" hypercapnia to build-up, whereas other patients did not. This controversy has faded out, and it seems now that hypercapnia per se has little influence in the outcome of these patients [12]. Before we can decide, in the controversy over sleep apnoea syndrome and upper airway resistance syndrome, whether they should be considered as separate entities or as part of the same continuum, new data are both needed and welcome.

\section{References}

1. Guilleminault C, Chowdhuri S. Upper airway resistance syndrome is a distinct syndrome. Am J Respir Crit Care Med 2000; 161: 1412-1413.

2. Douglas NJ. Upper airway resistance syndrome is not a distinct syndrome. Am J Respir Crit Care Med 2000; 161: $1413-1416$.

3. Guilleminault C, Eldrige F, Dement CW. Insomnia, narcolepsy and sleep apnea. Bull Physiopathol Respir 1972; 8: $1127-1138$.

4. Engleman H, Joffe D. Neuropsychological function in obstructive sleep apnoea. Sleep Medicine Reviews 1999; 3: 59-78.

5. Peppard PE, Young T, Palta M, Skatrud J. Prospective study of the association between sleep disordered 
breathing and hypertension. $N$ Engl J Med 2000; 342: $1378-1384$.

6. Peker Y, Hedner J, Kraiczi H, Loth S. Respiratory disturbance index. An independent predictor of mortality in coronary artery disease. Am J Respir Crit Care Med 2000; 162: 81-86.

7. Teran-Santos J, Jimenez-Gomez J, Cordero-Guevara J. The association between sleep apnea and the risk of traffic accidents. Cooperative group BurgosSantander. N Engl J Med 1999; 340: 847-851.

8. Gleeson $\mathrm{K}$, Zwillich CW, White DP. The influence of increasing ventilatory effort on arousal from sleep. $\mathrm{Am}$ Rev Respir Dis 1990; 142: 295-300.

9. Guilleminault C, Stoohs R, Clerk A, Cetel M,
Maistros P. A cause of excessive daytime sleepiness. The upper airway resistance syndrome. Chest 1993; 104: $781-787$.

10. Guilleminault C, Do Kim Y, Chowdhuri S, Horita M, Ohayon M, Kushida K. Sleep and daytime sleepiness in upper airway resistance syndrome compared to obstructive sleep apnoea syndrome. Eur Respir J 2001; 17: $838-847$.

11. Exar EN, Collop NA. The upper airway resistance syndrome. Chest 1999; 115: 1127-1139.

12. Saryal S, Celik G, Karabiyikoglu G. Distinctive features and long-term survival of reversible and chronic hypercapnic patients with COPD. Monaldi Arch Chest Dis 1999; 54: 212-216. 